\section{Flexible Fuel Vehicles: Providing a Renewable Fuel Choice}

\author{
Today, almost 8 million vehicles on U.S. highways are flexible fuel \\ vehicles (FFVs). These vehicles can operate on gasoline or blends \\ of gasoline and ethanol up to E85 (85\% ethanol, 15\% gasoline). \\ As a renewable fuel, ethanol offers significant advantages. It is \\ manufactured predominantly in the United States, made from \\ homegrown feedstocks, and is cleaner burning than gasoline.
}

\section{What is an FFV?}

An FFV, as its name implies, has the flexibility of running on more than one type of fuel. FFVs can be fueled with unleaded gasoline, E85, or any combination of the two. Like conventional gasoline vehicles, FFVs have a single fuel tank, fuel system, and engine. And they are available in a wide range of models such as sedans, pickups, and minivans. Lightduty FFVs are designed to operate with at least $15 \%$ gasoline in the fuel, mainly to ensure they start in cold weather.

FFVs are equipped with modified components designed specifically to be compatible with ethanol's chemical properties. In the illustration on the back, the main modifications for FFVs are described. These modifications ensure seamless operation and a long useful life across a wide range of ethanol blends.

Clean Cities posts a list of alternative fuel vehicles, including FFVs, on its Alternative Fuels and Advanced Vehicles Data Center (AFDC) Web site at www.afdc. energy.gov. To find out about available models, go to the Vehicles section of the AFDC and use the Light-Duty Vehicle Search.

\section{Can existing vehicles be converted to FFVs?}

Converting a conventional gasoline vehicle to one that runs on E85 is technically possible. FFV conversions need to be done by authorized companies and require certification by the U.S. Environ- mental Protection Agency (EPA) or the California Air Resources Board. Using noncertified conversions is illegal and may affect warranties.

For more information on the vehicle conversion process, refer to the EPA's Updated Certification Guidance for Alternative Fuel Converters on its Web site at www.epa.gov/otaq/cert/dearmfr/ cisd0602.pdf.

\section{Does E85 affect vehicle performance?}

FFVs operating on E85 generally handle and perform just as well as when fueled with gasoline. Sensors in the FFV system automatically prompt adjustments for fuel composition, so emissions and standard performance areas such as power and acceleration are not significantly affected by E85. One difference between E85 and gasoline, however, is fuel economy. Ethanol contains less energy per gallon, which translates into a reduction in fuel economy compared to gasoline. No matter what type of fuel is used, however, fuel mileage is affected by driving habits, weather, and other factors.

Standard test results for fuel economy of FFVs and their gasoline counterparts are posted on the combined EPA and U.S. Department of Energy Web site at www.fueleconomy.gov.

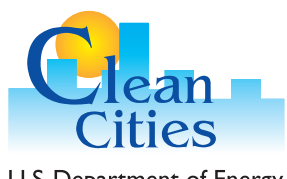

U.S. Department of Energy

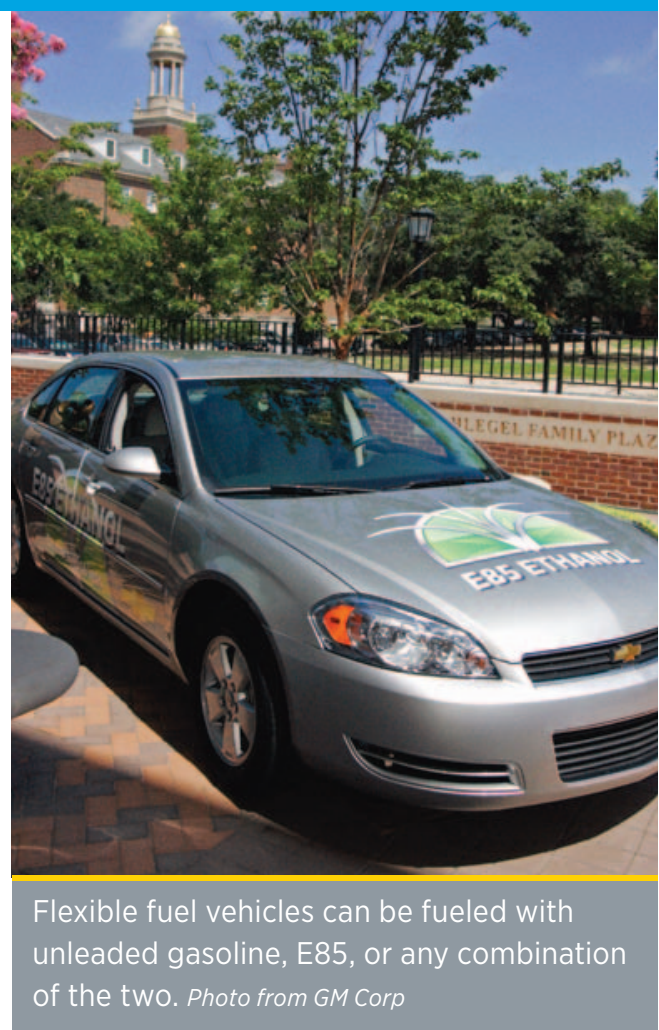

\section{What are the costs and benefits of using E85?}

Special features enabling vehicles to run on E85 can add a minimal cost to their purchase price. Because they have a solid performance history, manufacturers provide standard warranties for FFVs equal to those for gasoline vehicles at no additional charge.

Fuel, however, may be a cost factor. E85's reduced energy content compared to gasoline, as explained in the previous section, can increase fuel costs. This cost differential is highly variable because it is based on ethanol and gasoline price differences. Like gasoline, ethanol prices fluctuate and are set based on market supply and demand. This variability means that a driver may or may not experience a difference in overall fuel costs, depending on local pump prices. To compare the price of fueling with E85 versus gasoline, use the AFDC's Flexible Fuel Vehicle Cost Calculator at www.afdc.energy.gov/ afdc/progs/cost_anal.php?0/E85. 
Although your FFV's fuel economy on E85 is somewhat less than when operating on gasoline, a bonus for its use is lower greenhouse gas emissions. Using the GREET model, Argonne National Laboratory indicates in "Ethanol, The Complete Energy Lifecycle Picture" that greenhouse gas emissions are reduced approximately $15 \%$ when ethanol produced from corn is used. ${ }^{1}$ Using E85 also reduces $\mathrm{CO}_{2}$ emissions and provides significant reductions in emissions of many harmful toxics, including benzene, a known human carcinogen. However, E85 also increases emissions of acetaldehyde - a toxic pollutant. ${ }^{2}$ Additional testing is being completed to expand the understanding of the emissions impacts of E85.

\section{How are FFVs identified?}

Since September 2006, the Energy Policy Act of 2005 requires auto manufacturers to place a label inside the FFV fuel compartment that states the vehicle can run on either E85 or gasoline. Flexible-fuel capability also is outlined in the owner's manual and encoded in the vehicle identification number, or VIN.

\section{Where are E85 stations located?}

Stations offering E85 continue to increase across the nation. As of January 2010, more than 1,900 stations in 44 states sold E85. To find E85 stations throughout the country, check out the Alternative Fuel Station Locator at www.afdc.energy.gov/ stations, a database maintained by the AFDC. This easy-to-use database allows users to plot routes either across town or across the nation, showing E85 stations along the way.

Wang, Michael. Ethanol: The Complete Energy Lifecycle Picture, Argonne National Laboratory, March 2007.

Whitney, Kevin (Southwest Research Institute); Fernandez, Tony (U. S. Environmental Protection Agency). "Characterization of Cold Temperature VOC and PM Emissions from Flex Fuel Vehicles Operating on Ethanol Blends." Presented at the 17th CRC On-Road Vehicle Emissions Workshop, March 26-28, 2007.

\section{Resources}

Alternative Fuels and Advanced Vehicles Data Center: www.afdc.energy.gov

American Coalition for Ethanol: www.ethanol.org

Clean Cities:

www.cleancities.energy.gov

Fuel Economy: www.fueleconomy.gov

Growth Energy: www.e85fuel.com

Handbook for Handling, Storing, and Dispensing E85:

www.afdc.energy.gov/afdc/ethanol/ publications.htm/

Renewable Fuels Association: www.ethanolrfa.org

U.S. Environmental Protection Agency: www.epa.gov/otaq/consumer/fuels/ altfuels/altfuels.htm

\section{Flexible Fuel Vehicle Features}

Engine calibration updates: Fueling and spark advance calibrations are directed by vehicle computer to control combustion, enable cold start, and meet emissions requirements.

Internal engine parts: Piston rings, valve seats, valves, and other components must be made of ethanol-compatible materials that are designed to minimize the cleansing effects of alcohol fuels, which can wash lubrication from parts.

Fuel identifier system: System automatically senses the composition of the fuel and adjusts engine for varying

ethanol-gasoline blends.
Fuel system electrical connections and wiring: System must be electrically isolated and made of materials designed to handle ethanol's increased conductivity and corrosiveness (if exposed to fuel).
Fuel pump assembly: In-tank components must be made from ethanol-compatible materials and sized to handle the increased fuel flow needed to compensate for ethanol's lower energy density.

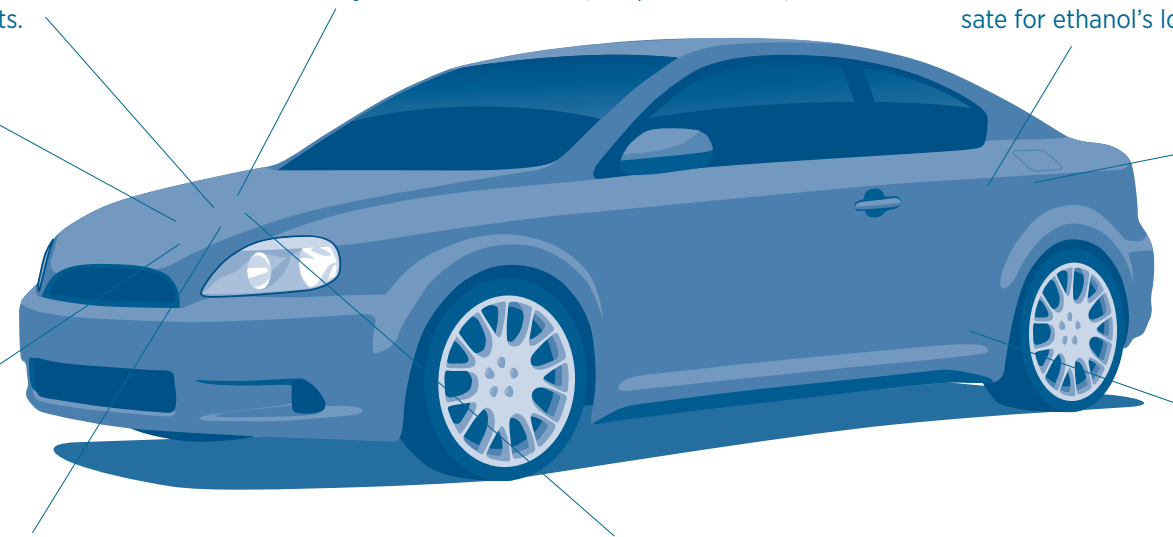

Fuel injection system: Must be made of ethanolcompatible materials and designed for higher flow to compensate for ethanol's lower energy density.
Fuel rail and fuel lines: Must be made of ethanol-compatible materials with seals, gaskets, and rubber fuel hoses rated for ethanol use.
Fuel filler assembly: Anti-siphon and spark arrestor features are included to handle ethanol's increased conductivity.

Fuel tank: Must be made of ethanol-compatible materials and designed to minimize evaporative emissions from ethanol.

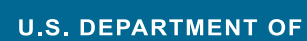
ENAROY Energy Efficiency \& Renewable Energy
Clean Cities Technical Response Service 800-254-6735 technicalresponse@icfi.com

Printed with a renewable-source ink on paper containing at least $50 \%$ wastepaper, including $10 \%$ post consumer waste.
Prepared by the National Renewable Energy Laboratory (NREL), a national laboratory of the U.S. Department of Energy, Office of Energy Efficiency and Renewable Energy; NREL is operated by the Alliance for Sustainable Energy, LLC.

DOE/GO-102010-3002 • March 2010 